\title{
Financial cost of the admissions for simultaneous pancreas-kidney transplant in a Brazilian Hospital ${ }^{1}$
}

\author{
Alcides Augusto Salzedas-Netto ${ }^{\text {I }}$ Adriano Miziara Gonzalez ${ }^{\text {II }}$, Ulysses Fagundes ${ }^{\text {III, }}$ Marcelo Moura Linhares ${ }^{\text {II }}$, Fernando Pompeu \\ Piza Vicentine $^{\mathrm{IV}}$, Luis Ramiro Núñez Romerov, José Luis Martinss ${ }^{\mathrm{VI}}$, José Osmar Medina Pestana ${ }^{\mathrm{VII}}$, Carlos Alberto Garcia Oliva ${ }^{\mathrm{VIII}}$ \\ DOI: http://dx.doi.org/10.1590/S0102-86502014001800009 \\ ${ }^{I} \mathrm{PhD}$, Associate Professor, Pediatric Surgery Division, Department of Surgery, Federal University of São Paulo (UNIFESP), Brazil. Conception and \\ design of the study, acquisition and interpretation of data, technical procedures, statistical analysis manuscript writing, critical revision. \\ IIPhD, Associate Professor, Gastroenterological Surgery Division, Department of Surgery, UNIFESP, Sao Paulo-SP, Brazil. Conception and design of \\ the study, acquisition and interpretation of data, technical procedures. \\ IIIMaster, Physician Manager, Hypertension and Kidney Hospital, Sao Paulo-SP, Brazil. Conception and design of the study, acquisition of data. \\ ${ }^{\mathrm{IV}}$ Master, Fellow PhD degree, Postgraduate Program in Interdisciplinary Sciences Surgery, Gastroenterological Surgery Division, Department of Surgery, \\ Federal University of São Paulo - UNIFESP, São Paulo, Brazil. Interpretation of data; technical procedures; statistical analysis; manuscript writing \\ ${ }^{v}$ Fellow observer Gastroenterological Surgery Division, Department of Surgery, UNIFESP, Sao Paulo-SP, Brazil. Acquisition and interpretation of \\ data; statistical analysis, manuscript writing. \\ ${ }^{V} \mathrm{PhD}$, Full Professor, Pediatric Surgery Division, Department of Surgery, UNIFESP, Sao Paulo-SP, Brazil. Conception and design of the study, \\ acquisition of data, critical revision. \\ ${ }^{V I I} P h D$, Full Professor, Nephrology Division, Department of Internal Medicine, UNIFESP, Sao Paulo-SP, Brazil. Conception and design of the study, \\ acquisition of data, critical revision. \\ VIIIPhD, Associate Professor, Department of Pediatric, UNIFESP, Sao Paulo-SP, Brazil. Conception and design of the study, acquisition of data, critical revision.
}

\begin{abstract}
PURPOSE: To perform a cost analysis of simultaneous pancreas-kidney transplantation (SPKT) in a Brazilian hospital.

METHODS: Between January 2008 and December 2011, 105 consecutive SPKTs at the Hospital of Kidney and Hypertension in Sao Paulo were evaluated. We evaluated the patient demographics, payment source (public health system or supplementary system), and the impact of each hospital cost component. The evaluated costs were corrected to December 2011 values and converted to US dollars. RESULTS: Of the 105 SPKT patients, 61.9\% were men, and 38.1\% were women. Eight patients died, and 97 were discharged (92.4\%). Eighty-nine procedures were funded by the public health system. The cost for the patients who were discharged was $\$ 18.352 .27$; the cost for the deceased patients was $\$ 18.449 .96(\mathrm{p}=0.79)$. The FOR for SPKT during this period was positive at $\$ 5,620.65$. The costs were distributed as follows: supplies, 36\%; administrative costs, 20\%; physician fees, 15\%; intensive care unit, 10\%; surgical center, $10 \%$; ward, $9 \%$.
\end{abstract}

CONCLUSION: Mortality did not affect costs, and supplies were the largest cost component.

Key words: Pancreas Transplantation. Kidney Transplantation. Costs and Cost Analysis. 


\section{Introduction}

The first pancreas transplant in the world was performed in 1966 in the United States by surgeons William D. Kelly and Richard C. Lillehei at the Hospital of the University of Minnesota in Minneapolis ${ }^{1}$. This surgery was a duodenum/pancreas transplantation simultaneously with kidney transplantation. Since then, simultaneous pancreas-kidney transplantation has evolved technically, and with the development of new immunosuppressive therapy, this technique has become an efficient and accepted method for managing patients with end-stage renal disease and diabetes mellitus throughout the world ${ }^{2}$.

Simultaneous pancreas-kidney transplantation (SPKT) has a higher technical complication rate compared with other transplants, which increases the cost of the procedure. The Brazilian health system has two types of health insurance: a public health system (i.e., Unique Health System, SUS) and a supplementary system (SS); the majority of patients belong to the former. It is important to transplant teams, institutions, and the health system to assess the economic viability of SPKT.

Few data are available regarding the finances of SPKT. Gruessner et $a .^{3}$ evaluated the risk factors associated with increased hospital charges for pancreas transplantation and stated a need for a hospital cost analysis. The objective of the current study was to perform a cost analysis of SPKT in a Brazilian hospital, including demographic variables, payment source (SUS or SS), and the impact of each hospital cost component.

\section{Methods}

After receiving approval from the institutional ethics committee and following the principles outlined in the Declaration of Helsinki, records from 105 SPKTs performed between January 1, 2008 and December 31, 2011 at the Hospital of Kidney and Hypertension in Sao Paulo were retrospectively reviewed. Clinical data, including hospital time, complications, and other information were obtained from the medical records.

Inpatient financial data concerning the combined physician procedural and nonprocedural reimbursements and total hospital costs (direct and indirect) were obtained from the internal cost accounting database at the Hospital of Kidney and Hypertension. The costs included SPKT admissions without preand postoperative evaluations. All pharmaceutical costs, including prolonged inpatient and outpatient intravenous antibiotics, were incorporated into the financial data. Financial data were collected from the day of transplantation (including the transplant operation) until the day that the patient was discharged. The data were analyzed separately for each of the two Brazilian health systems (SUS and SS).

All costs were evaluated monthly, converted to dollars, and then corrected to the official dollar value for December 2011, according to the IPCA and the IBGE; therefore, the values are expressed in US dollars and as medians.

\section{Statistical analysis}

The relationships among the variables were assessed using an unpaired Student's t-test for continuous variables and a chi-squared analysis for categorical variables. Differences in financial data medians were assessed using the Mann-Whitney U-test. All statistical analyses were performed using StatView (version 5.0.1) (Abacus Concepts, Inc., Berkley, CA, USA).

\section{Results}

There were no significant age differences between the patients who were discharged and those who died. Men comprised a relatively higher percentage of patients, and there were no significant cost differences based on gender.

There was a significant difference in the mean total cost between the two payment sources, $\mathrm{p}=0.007$ (Table 1).

TABLE 1 - Mean cost per payment source (values in US dollars).

\begin{tabular}{cccccc}
\hline & N & Total Cost & Mean & Variance & $\begin{array}{c}\text { Standard } \\
\text { Deviation }\end{array}$ \\
\hline SS & 16 & 402.860 .4 & 25.178 .7 & 59182422.0 & 7693.0 \\
SUS & 89 & 1.775 .147 .6 & 19.945 .4 & 51612832.4 & 7184.2 \\
\hline
\end{tabular}

Eight patients died, and 97 were discharged (92.4\%). All death cases were observed in the public health system (SUS) group. Death was not associated with significantly increased hospital charges, costs and reimbursements. The mean cost for the patients who were discharged was $\$ 18.352 .27$, and the mean cost for those who died was $\$ 18.449 .96(\mathrm{p}=0.79)$.

The length of stay in the ward was 8.35 days at a mean cost of $\$ 1484.72$, representing $10 \%$ of the total cost, with no difference between the two payment sources. The length of ICU stay represented $10 \%$ of the cost, with a mean of 3.05 days at a cost of $\$ 1398.05$. Supplies were the major cost component, accounting for $36 \%$ of the total cost, with an average value of $\$ 6.172$. The distribution of the percentages and the component costs is presented in Figure 1. 


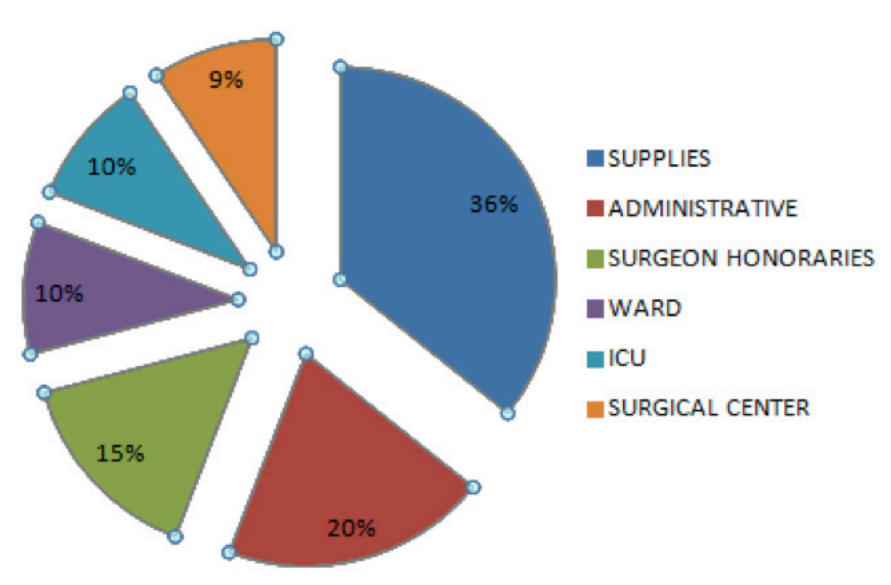

FIGURE 1 - Percentage distribution of costs by component.

The surgical time of 6.33 hours cost $\$ 1876.62$ and, along with the intensive care unit (ICU) and hospital stays, represented the lower-cost components; in contrast, supplies and administration were higher cost components.

Table 2 compares the cost per component for each of the payment sources. Although there are cost differences (mainly at the supply level), these differences were not statistically significant.

TABLE 2 - Financial data of patients with SUS vs. SS per component (values in dollars).

\begin{tabular}{cccc}
\hline & SUS & SS & Difference \\
\hline Supplies & 6.851 .67 & 10.630 .38 & -3.778 .71 \\
Administrative costs & 3.989 .1 & 5.035 .76 & -1.046 .66 \\
Surgeons' Fees & 3.120 .14 & 3.132 .57 & -12.43 \\
Ward & 2.037 .41 & 2.366 .38 & -328.97 \\
ICU & 2.037 .86 & 1.827 .61 & 210.25 \\
Surgical center & 1.909 .29 & 2.186 .08 & -276.79 \\
\hline
\end{tabular}

To study the economic feasibility of the procedure, the billing was compared to the procedure cost and was analyzed by separating the data by the payment source. The FOR was positive for both groups and averaged $\$ 5620.65$. However, when differentiating between the payment sources, a higher gain was found in the SUS; this difference was statistically significant $(\mathrm{p}=0.002)$.

\section{Discussion}

To establish the economic feasibility of SPKT, it is to measure its costs and profits. In a systematic literature search of United States, European, and Latin American publications, little data are available concerning the finances of SPKT. Troppman et $a .^{5}$ studied the complication rates associated with pancreas transplantation but noted the need for a detailed financial analysis.

Englebese et $a l .{ }^{6}$ investigated the influence of postoperative complications on the financial results of pancreas transplantation based on three variables; the authors found a $\$ 15.514$ difference between the patients with complications and without complications. The financial cost was higher for the patients who presented with surgical complications, at a cost of $\$ 17.363$; the authors concluded that transplant surgical quality improvement might benefit patients and $\operatorname{costs}^{6}$. In our study, the only complication measured was death, and no cost difference was found when the deceased patients were compared with the patients discharged alive.

Of the eight patients who died, the causes were sepsis $(n=4)$, cardiovascular events $(n=3)$, and hemorrhagic shock $(n=1)$. It is possible that there is no cost difference between the deceased patients and those who were discharged because early deaths shortened the hospitalizations of these patients.

There are different cost components for pancreas transplantation. We found no other studies in which these components were analyzed individually. Our findings demonstrated a great difference in the cost of supplies and administration vs the cost of medical and nursing care, which is most likely caused by the enormous amount of logistics required for SPKT and the associated high cost.

Vonlanthen et al. ${ }^{7}$ performed a cost study of patients who underwent major surgeries (i.e., liver, pancreas, colorectal and gastric bypass surgeries); the objective was to determine the impact of surgical and post-surgical complications during the hospital stay on the final financial outcome. The authors demonstrated that postoperative complications greatly impact the financial costs and outcomes of the procedure $(\mathrm{p}=0.001)$.

There was also a higher cost for SPKT in patients with SS, and the difference was significant; however, the FOR margin was higher in this group. We believe that the lower gain margin in the SUS is offset by the high volume of this patient group. Cohn et $a l .{ }^{8}$ found similar data in their study, which described a higher cost of complications for patients with Medicare insurance.

\section{Conclusions}

Simultaneous pancreas-kidney transplantation (SPKT) is an economically viable process for Brazilian health institutions. The mortality rate does not indicate an increase in costs for the procedure. The highest cost is for medical supplies. It is necessary to assess the impact of all complications to analyze the cost of SPKT. 


\section{References}

1. Teixeira E, Monteiro G, De Cenzo M, Teixeira A, Bergan JJ Transplantation of the isolated pancreas: report on the first human case. Bull Soc Int Chir. 1970 Nov-Dec;29(6):337-44. PMID: 4934744.

2. Sutherland DER, Gruessner RW, Gruessner AC. Pancreas transplantation for treatment of diabetes mellitus. World J Surg. 2001 Apr;25:487-96. PMID: 11344403.

3. Gruessner AC, Troppmann C, Sutherland DE, Gruessner RW. Donor and recipient risk factors significantly affect cost of pancreas transplants. Transplant Proc. 1997 Feb-Mar;29:656-7. PMID: 9123464.

4. Kahl A, Bechstein WO, Frei U. Trends and perspectives in pancreas and simultaneous pancreas and kidney transplantation. Curr Opin Urol. 2011 Mar;11(2):165-74. PMID: 11224747.

5. Troppmann C, Gruessner AC, Dunn DL, Sutherland DE, Gruessner RW. Surgical complications requiring early relaparotomy after pancreas transplantation: A multivariate risk factor and economic impact analysis of the cyclosporine era. Ann Surg. 1998 Feb;227:25568. PMID: 9488525.

6. Englesbe MJ, Pelletier SJ, Kheterpal S, O'reilly M, Campbell DA Jr. A call for a national transplant surgical quality improvement program. Am J Transplant. 2006 Apr;6:666-70. PMID: 16539622.

7. Vonlanthen R, Slankamenac K, Breitenstein S, Puhan MA, Muller MK, Hahnloser D, Hauri D, Graf R, Clavien PA. The impact of complications on costs of major surgical procedures a cost analysis of 1200 patients. Ann Surg. 2011 Dec;254:907-13. doi: 10.1097/ SLA.0b013e31821d4a43.
8. Cohn JA, Englesbe MJ, Ads YM, Paruch JL, Pelletier SJ, Welling TH, Sonnenday CJ, Magee JC, Punch JD, Campbell DA Jr, Sung RSJ. Financial implications of pancreas transplant complications: a business case for quality improvement. Am J Transplant. 2007 Jun;7(6):1656-60. PMID: 17425623.

\section{Correspondence:}

Alcides Augusto Salzedas-Netto

Rua Borges Lagoa, 1080 cjs 201/202

04038-002 São Paulo - SP Brasil

Tel/Fax: (55 11)5576-4053

alcidessalzedas@yahoo.com.br

Received: June 10, 2014

Review: Aug 12, 2014

Accepted: Sep 11, 2014

Conflict of interest: none

Financial source: none

${ }^{1}$ Research performed at Gastroenterological Surgery and Pediatric Surgery Divisions, Department of Surgery, Federal University of Sao Paulo (UNIFESP), Brazil. 